\title{
Pattern of neurological disease seen among patients admitted in tertiary care hospital
}

\author{
Rajib Nayan Chowdhury ${ }^{1}$, ATM Hasibul Hasan ${ }^{1,2^{*}}$, Yusuf Ur Rahman', Shafikul Islam Khan ${ }^{1}$, Ahmed Riyad Hussain ${ }^{1}$ \\ and Shamim Ahsan ${ }^{1}$
}

\begin{abstract}
Background: Neurologic disorders are not uncommon at in patient departments of different hospitals. We have conducted the study to see the pattern and burden of neurologic disorders at different inpatient departments of a tertiary care centre.

Methodology: This retrospective observational study was carried out from the records and referral notes of neurology department of Dhaka Medical College Hospital (DMCH) from July 2011 to June 2012. A total 335 patients were evaluated by consultant neurologists during this period.

Result: Majority of the patients (59.7\%) presented after the age of forty years. The mean age at presentation was $45.11 \pm 17.3$ years with a male predominance (63.3\%). Stroke was the most common condition (47.5\%) observed at referral, followed by seizure (9.3\%), disease of spinal cord (7.8\%) and encephalopathy (6.3\%). Even after consultation, 30 patients remained undiagnosed and 6 were diagnosed as functional disorder. Department of Medicine (231, $69 \%)$ and Cardiology $(61,18.2 \%)$ made most of the calls. More than half (56\%) of the stroke patients were referred from medicine and one third (35.2\%) from cardiology. Seizure (67.7\%), problem in spinal cord (92.3\%), coma (50\%), encephalopathy (57.1\%), motor neuron disease (MND) (72.7\%) were common reasons for referral from department of Medicine. Whereas patients with cord disease (7.3\%), CNS tumor (40\%), seizure disorder (6.5\%) and stroke (3.8\%) were referred from surgery. Department of Obstetrics and Gynecology sought help for stroke (2.5\%), seizure (12.9\%), MND (27.3\%), coma (16.7\%) and encephalopathy (9.5\%).

Hypertension, diabetes, ischemic heart disease, dyslipidaemia and respiratory problem were significantly associated co-morbid conditions in stroke patients (at $95 \% \mathrm{Cl}, p$ value is $<0.001,<0.01,<0.001,<0.05,<0.05$ respectively). Hematological disorders were common association among patients with cord problem $(<0.05)$.

Conclusion: Wide ranges of neurological problems are often managed by physicians and surgeons, especially those from medicine and cardiology. Where ever available consultation from neurologists can help in diagnosing and managing these cases.
\end{abstract}

Keyword: Neurologic disease

\section{Background}

The overall global burden of neurologic disease is approximately $20 \%$, the majority being in the developing countries [1]. The incidence of neurologic disorder in UK is $0.6 \%$ with an overall $6 \%$ lifetime prevalence rate [2]. Many patients with acute or chronic neurological problems often get admitted under general medicine and other departments. Some with other primary diagnosis may

\footnotetext{
* Correspondence: parag007us@gmail.com

${ }^{1}$ Dhaka Medical College Hospital, Dhaka, Bangladesh

2Department of Medicine, Dhaka Medical College Hospital, Dhaka, Bangladesh
}

also develop neurological complication due to course of illness or as a part of complication. Approximately 15-20\% of all medical admission and 40\% inpatients in medical wards are neurologic problems that often require consultation even in UK [3-6]. Despite these statistical logics whenever available, expert neurologic assessment and management can alter the working diagnosis and can have a positive impact on overall hospital management [7]. Diagnostic errors by non neurologists are not very uncommon, especially regarding epilepsy and other non-organic illness $[8,9]$. Retrospective studies have also shown that
C Bïomed Central

(c) 2014 Chowdhury et al.; licensee BioMed Central Ltd. This is an Open Access article distributed under the terms of the Creative Commons Attribution License (http://creativecommons.org/licenses/by/2.0), which permits unrestricted use, distribution, and reproduction in any medium, provided the original work is properly credited. 
diagnostic change following neurology consultation is seen in $32-50 \%$ of inpatient referrals [10-12]. Studies have also proved that a liaison with neurology consultation may improve inpatient care in UK $[9,13]$.

Neurology was introduced as a specialty in Bangladesh during the 1960s'. Apart from infection and malnutrition, an excess burden of cerebrovascular disease and stroke at an early age denotes a higher risk of mortality and morbidity in Bangladesh [14,15]. As neurologic disorders are quite common among all medical admissions in $\mathrm{DMCH}$ and there are lack of facilities elsewhere in the country, varieties of neurological problems are referred to Dhaka Medical College Hospital (DMCH). Previously we did not have any published data regarding the neurology consultation pattern in Bangladesh. The available data on this issue are mostly from European countries. We therefore tried to audit the nature of neurologic involvement among patients admitted in different departments and liaison of neurology with these departments through this referral system.

\section{Methods}

This is a retrospective observational study. We reviewed the records and referral notes from Neurology department of Dhaka Medical College Hospital (DMCH) from July 2011 to June 2012. Dhaka Medical College Hospital, the centre of excellence and one of the highest centers of referral for any health related issue has 1600 inpatient beds. In addition to Department of Medicine, Surgery, Obstetrics and Gynaecology, the hospital has enriched departments like Neurology, Cardiology, Gastroenterology etc. Neurology department has 22 inpatient beds. Our study population included 335 patients from the hospital records over the period of one year. All new inpatient referrals to neurology in $\mathrm{DMCH}$ were eligible for inclusion. Each of the referred patients was examined by the Consultant Neurologist who attended the referral. Patient's problem was diagnosed clinically with proper history, examination and with help of investigations in required cases. Information regarding the demographic and clinical profile was gathered through a questionnaire. Neurological diagnosis was categorized under 12 broad headings (Table 1 ). The research protocol was reviewed and accepted by the ethical review committee of Dhaka Medical College. Analysis was done using SPSS version 16.0. At 95\% CI, $p$ value $<0.05$ was considered significant.

\section{Results}

A total of 335 patients were seen by neurologists within this period of time. Most of the patients (59.7\%) presented after the age of forty years. Only $2(0.6 \%)$ patients were below 10 years. The distribution of patients were more or less similar in different age groups from 21 years to those above 60 years $(15-18 \%)$. The mean age at presentation was $45.11 \pm 17.3$ years. The male patients $(63.3 \%)$ predominated with a sex ratio was almost 2:1 (Table 2). Stroke was the most common condition $(149,47.5 \%)$ observed at referral, followed by seizure (31, 9.3\%), disease of spinal cord $(26,7.8 \%)$ and encephalopathy (21, 6.3\%). But CNS infection (3.9\%), peripheral neuropathy (3.9\%), coma (3.6\%) and MND (3.3\%) were less common. Conditions like dementia (1.5\%), tumor (1.5\%) and GBS $(0.9 \%)$ were rarely consulted. Even after consultation, 30 patients remained undiagnosed at first visit and 6 patients had non organic

Table 1 Distribution of diseases from different departments

\begin{tabular}{|c|c|c|c|c|c|c|}
\hline \multirow{2}{*}{$\begin{array}{l}\text { Disease } \\
\text { Diagnostic break down (number, \%) }\end{array}$} & \multicolumn{6}{|c|}{ Number \& percentage of patients from different departments } \\
\hline & Medicine & Surgery & Obs \& Gynae & Cardiology & ICU & Burn and plastic surgery \\
\hline Stroke $(159,47.5)$ & $89(56)$ & $6(3.8)$ & $4(42.5)$ & $56(35.2)$ & $2(1.3)$ & $2(1.3)$ \\
\hline Seizure $(31,9.3)$ & $21(67.7)$ & $2(6.5)$ & $4(12.9)$ & 0 & 0 & $4(12.9)$ \\
\hline CNS infection $(13,3.9)$ & $13(100)$ & 0 & 0 & 0 & 0 & 0 \\
\hline Peripheral neuropathy $(13,3.9)$ & $13(100)$ & 0 & 0 & 0 & 0 & 0 \\
\hline $\operatorname{GBS}(3,0.9)$ & $3(100)$ & 0 & 0 & 0 & 0 & 0 \\
\hline $\operatorname{MND}(11,3.3)$ & $8(72.7)$ & 0 & $3(27.3)$ & 0 & 0 & 0 \\
\hline Cord disease $(26,7.8)$ & $24(92.3)$ & $2(7.3)$ & 0 & 0 & 0 & 0 \\
\hline Dementia $(5,1.5)$ & $5(100)$ & 0 & 0 & 0 & 0 & 0 \\
\hline Tumor $(5,1.5)$ & $3(60)$ & $2(40)$ & 0 & 0 & 0 & 0 \\
\hline Coma $(12,3.6)$ & $6(50)$ & 0 & $2(16.7)$ & 0 & $4(33.3)$ & 0 \\
\hline Encephalopathy $(21,6.3)$ & $12(57.1)$ & $4(19)$ & $2(9.5)$ & $3(14.3)$ & 0 & 0 \\
\hline Functional $(6,1.8)$ & $6(100)$ & 0 & 0 & 0 & 0 & 0 \\
\hline Undiagnosed clinically $(30,9)$ & 28(93.3) & 0 & $2(6.7)$ & 0 & 0 & 0 \\
\hline $\begin{array}{l}\text { Total number and (\%) of patients } \\
\text { within different departments }\end{array}$ & $231(69 \%)$ & $16(3.2 \%)$ & $15(3 \%)$ & $61(18.2 \%)$ & $6(1.8 \%)$ & $6(1.8 \%)$ \\
\hline
\end{tabular}


Table 2 Socio demographic profile of the patients $(\mathrm{N}=335)$

\begin{tabular}{cccc}
\hline Parameter & & $\mathbf{n}$ & $\%$ \\
\hline Age & $0-10 y r$ & 2 & \\
& $11-20 y r s$ & 25 & 0.6 \\
& $21-30$ yrs & 56 & 16.5 \\
& $31-40$ yrs & 52 & 15.5 \\
& $41-50$ yrs & 87 & 26 \\
& $51-60$ yrs & 62 & 18.5 \\
& $>60$ yrs & 51 & 15.2 \\
& & & \\
& Male & 212 & 63.3 \\
& Female & 123 & 36.7 \\
\hline
\end{tabular}

Table-2: Shows the age group and sex distribution of patients. Most common age of presentation was after 40 yrs.

(functional) diagnosis (Table 1). Department of Medicine was the largest consultation seeker (231,69\%), followed by department of Cardiology (61, 18.2\%). Number of patients referred from Surgery (16), Obstetrics and Gynecology (15), ICU (6) and Burn \& Plastic Surgery (6) were very few. More than half $(56 \%)$ of the stroke patients were referred from medicine and one third (35.2\%) from cardiology. Seizure (67.7\%), problem in spinal cord (92.3\%), coma (50\%), encephalopathy (57.1\%) MND (72.7\%) were common reason for referral from department of Medicine. Some diseases like CNS infection, peripheral neuropathy, GBS, dementia were referred only from this department. Department of Cardiology took help only for stroke (35.2\%) and encephalopathy (14.3\%). Patients with cord disease (7.3\%), CNS tumor (40\%), seizure disorder (6.5\%) and stroke (3.8\%) were referred from surgery. Department of Obstetrics and Gynecology sought help for stroke (2.5\%), seizure (12.9\%), MND (27.3\%), coma (16.7\%) and encephalopathy (9.5\%) (Table 1).

Hypertension, diabetes, ischemic heart disease, dyslipidaemia and respiratory problem were significantly associated co-morbid conditions in stroke patients (at 95\% CI, $p$ value is $<0.001,<0.01,<0.001,<0.05,<0.05$ respectively. Hematological disorders (especially disorders with extramedullary haematopoiesis) were common association among patients with cord problem (Table 3).

\section{Discussion}

Though the number of neurologists (only 86) [16] has increased over last decade in Bangladesh, it is still not enough. Many patients with neurological problems are often dealt by internists and others from different specialties. Studies have proved the usefulness of liaison with neurology, especially in teaching hospitals $[4,11,13]$ and the patient care also improved with specialist management. The length of hospital stays was also shortened in study by Forbes et al [4]. Moeller et al [17] also provided enough data to prove the reliability of initial neurology referral. But we didn't have any similar study in our setting. So we tried to get a glimpse of our neurology service in this teaching hospital. This paper represents a comprehensive survey of inpatient admission of neurological problems and referral seeking behavior of different departments. It gives a

Table 3 Common co-morbidities observed among patients

\begin{tabular}{|c|c|c|c|c|c|c|c|c|}
\hline \multirow[b]{2}{*}{ Disease } & \multicolumn{8}{|c|}{ Percentage of patient with co-morbidity } \\
\hline & HTN & DM & IHD & Arryhtmia & CKD & Dyslipidaemia & $\begin{array}{l}\text { Respiratory } \\
\text { disorder }\end{array}$ & $\begin{array}{c}\text { Haematological } \\
\text { disorder }\end{array}$ \\
\hline Stroke (159) & 83.3 & 100 & 85.2 & 66.7 & 66.7 & 100 & 33.3 & 0 \\
\hline Seizure (31) & 2.1 & 0 & 0 & 0 & 0 & 0 & 0 & 20 \\
\hline CNS infection (13) & 0 & 0 & 0 & 0 & 9.5 & 0 & 16.7 & 0 \\
\hline Peripheral neuropathy (13) & 0 & 0 & 0 & 0 & 0 & 0 & 16.7 & 0 \\
\hline GBS (3) & 0 & 0 & 0 & 0 & 0 & 0 & 0 & 0 \\
\hline MND (11) & 0 & 0 & 0 & 0 & 0 & 0 & 0 & 0 \\
\hline Cord disease (26) & 0 & 0 & 2.5 & 0 & 0 & 0 & 16.7 & 50 \\
\hline Dementia (5) & 3.1 & 0 & 6.2 & 0 & 0 & 0 & 0 & 0 \\
\hline Tumor (5) & & 0 & 0 & 0 & 0 & 0 & 16.7 & 0 \\
\hline Coma (12) & 2.1 & 0 & 2.5 & 33.3 & 9.5 & 0 & 0 & 0 \\
\hline Encephalopathy (21) & 2.1 & 0 & 3.7 & 0 & 0 & 0 & 0 & 0 \\
\hline Functional (6) & & 0 & 0 & 0 & 0 & 0 & 0 & 0 \\
\hline Undiagnosed clinically (30) & 7.3 & 0 & 0 & 0 & 14.3 & 0 & 0 & 30 \\
\hline Total number of patients with co-morbidities & 96 & 16 & 81 & 6 & 21 & 16 & 12 & 10 \\
\hline$P$ value & $<0.001$ & $<0.01$ & $<0.001$ & $>1$ & $>0.05$ & $<0.05$ & $<0.05$ & $<0.001$ \\
\hline
\end{tabular}


transparent idea about the burden of neurological cases in these departments.

The patient demographic profile reflects that most of the referral and consultation sought was from the older (the mean age, $45.11 \pm 17.3$ years) and male patients. The distribution was similar to Gajurel et al [18] from India. Probably the age and sex related increase in cerebrovascular event has made the neurological problems a common ailment in many studies including this one $[7,12]$. A total of 33226 patients were admitted in Department of Medicine of $\mathrm{DMCH}$, the largest fraction (14.3\%) of which was stroke [19] and not surprisingly the most common cause of referral, irrespective of the departments was stroke $(47.5 \%)$ which is also similar $(49.5 \%)$ to the report of Gujral et al [18]. But the total burden of neurological problem in Medicine is not known. Though most (231) of the patients were referred from the department of medicine to neurology, it accounts for only $0.69 \%$ of all inpatient admissions [19]. Even the data from death and discharge profile of The Royal College of Physicians of London, revealed that the majority of patients with serious neurological disease were under the care of physicians (and sometimes surgeons) in disciplines other than neurology [20]. A significant portion of referral (18.2\%) came from department of cardiology, especially for patients with stroke (35.2\%), which can be explained by the common patho-physiology of vascular events. Stroke as being major killer and cause of disability in developing world like us, it was the commonest cause for referral. Stroke causes 1.6 million death in china and 0.6 million death in India [21]. Other than stroke, seizure (9.3\%) was the next common event for consultation seeking. In contrary to this most the European studies except for the Irish, reported epilepsy as a major cause of referral, followed by stroke $[7,19,22,23]$. The Irish reporting had stroke $(22.7 \%)$ and epilepsy $(10.2 \%)$ as two most common causes for referral. This is probably partly due to the difference in disease prevalence and the methodology applied in these studies. Although, the annual incidence of epilepsy (50 per 100000 population) in developing countries is twice that of the developed world [24], the increased burden of stroke has outnumbered other diseases in our study. The frequency of other neurological problems like, cord disease, encephalopathy, CNS infection, peripheral neuropathy was very low. The pattern these less common diseases, was similar to the above mentioned European studies $[7,19,22,23]$.

Seizure was also common cause of referral from the department of Obstetrics \& Gynecology and Burn \& Plastic surgery. This is mostly due to referral from eclampsia ward and that the patients with epilepsy often encounter burn accidentally during a seizure event. Unfortunately even after the efforts by neurologists about $9 \%$ of the patients remained undiagnosed. Hypertension, DM, ischemic heart disease, dyslipidaemia, hematological disorder and respiratory disorders were significant ( $p$ value $<0.05$ ) association with neurological problems. All these are common comorbidities for vascular events eg stroke [25].

We had some limitations in this study. First of all, patients were seen only once by the neurologist. So follow up data was unavailable. Secondly, each patient was consulted by a single neurologist. So there is chance of diagnostic variability. Further studies involving large cohorts and cross checking neurologists are required to validate these findings.

\section{Conclusion}

A significant portion of neurological workload is still managed by non neurologist physicians and the pattern of disease includes the entire possible range of neurological problems. The neurologists can make a valuable contribution to the diagnosis and management of neurological problems through the medium of neurological ward referrals.

\section{Competing interests}

The authors declare that they have no competing interests.

\section{Authors' contributions}

RNC was involved concept, data collection and revision of manuscript for this study. ATMHH was involved in data analysis and writing the article. The rest were involved in design, data collection and analysis. All the authors have read and approved the final version of the manuscript.

\section{Acknowledgements}

We are really thank full to all those departments for referring the patients to us.

Received: 4 December 2012 Accepted: 28 March 2014

Published: 31 March 2014

\section{References}

1. Burton KJ, Allen S: A review of neurological disorders presenting at a paediatric neurology clinic and response to anticonvulsant. Ann Trop Pediatric 2003, 23:139-143.

2. MacDonald BK, Cockerell OC, Sander JWAS, Shorvon SD: The incidence and lifetime prevalence of neurologic disorder in a prospective community-based study in the UK. Brain 2000, 123:665-676.

3. Playford ED, Crawford P, Munro PS: A survey of neurological disability at a district general hospital. Br J Clin Pract 1994, 48:304-306.

4. Forbes R, Craig J, Callender M, Patterson V: Liaison neurology for acute medical admissions. Clin Med 2004, 4:290.

5. Craig J, Patterson V, Roche L, Jamison J: Accident and emergency neurology: time for a reappraisal? Health Trends 1997, 29:89-91.

6. Morrow J, Patterson VH: The neurological practice of a district general hospital. J Neurol Neurosurg Psychiatry 1987, 50:1397-1401.

7. McColgan P, Carr AS, McCarron MO: The value of a liaison neurology service in a district general hospital. Postgrad Med J 2010. doi:10.1136/ pgmj.2010.106971.

8. Chadwick D, Smith D: The misdiagnosis of epilepsy. BMJ 2002, 324:495e6.

9. Fitzpatrick AS, McCarron MO: Inpatient use and usefulness of a district general hospital neurologist. Postgrad Med J 2008, 84:109e10.

10. Hillen ME, Sage Jl: Proving the worth of neurologists. Neurology 1996, 46:276e7.

11. Steiger MJ, Enevoldson TP, Hammans SR, Ginsberg L: Influence of obtaining a neurological opinion on the diagnosis and management of hospital inpatients. J Neurol Neurosurg Psychiatry 1996, 61:653e4.

12. Costello DJ, Renganathan R, O'Hare A, Murray B, Lynch T: Audit of an inpatient neurology consultation service in a tertiary referral centre: value of the consulting neurologist. Ir Med J 2005, 98(5):134-137. 
13. Craig J, Chua R, Russell C, Wootton R, Chant D, Patterson V: A cohort study of early neurological consultation by telemedicine on the care of neurological inpatients. J Neurol Neurosurg Psychiatry 2004, 75:1031e5.

14. MacKay J, Mensah GA: The Atlas of Heart Disease and Stroke. Geneva: WHO Press; 2004.

15. Bhopal R, Rahemtulla T, Sheikh A: Persistent high stroke mortality in Bangladeshi populations. BMJ 2005, 331:1096-1097.

16. Habib M: Members Directory 2012. Bangladesh: Society of Neurologists.

17. Moeller JJ, Kurniawan J, Gubitz GJ, Ross JA, Bhan B: Diagnostic accuracy of neurological problems in the emergency department. Can J Neurol Sci 2008, 35:335e41.

18. Gajurel BP, Parajuli P, Nepali R, Oli KK: Spectrum of neurological disorders admitted in Tribhuvan University Teaching Hospital Maharajgunj. J Inst Med 2012, 34(3):50-53.

19. Mallik MU, Parvez SI: Disease profile 2011: Internal Medicine. In Year Book 2011. Edited by Azad KAK. Department of Medicine, Dhaka Medical Colledge Hospital. Publisher: Beximco Pharma; 2011.

20. Royal College of Physicians: The district general hospital as a resource for the provision of Neurological Services. London: Royal College of Physicians; 1996.

21. Murray CIL, Lopez AD: The Global Burden of Disease: The World Health Organization and The World Bank. Cambridge, Mass: Harvard University Press; 1996.

22. Weatherall MW: Acute neurology in a twenty-first century district general hospital. J R Coll Physicians Edinb 2006, 36:196-200.

23. Chapman FA, Pope AE, Sorensen D, Knight RS, Al-Shahi Salman R: The uses of a rapid access neurology clinic. J R Coll Physicians Edinb 2009, 39:296-300.

24. Sanders JWAS, Shorvon FD: Epidemiology of the epilepsies. J Neurol Neurosurg Psychiatry 1996, 61:433-443.

25. Mondol BA, Chowdhury RN, Rahman KM, Khan SU, Hasan ATM H, Habib MA, Hoque MA, Haque B, Khan MZR, Habib M, Mohammad QD: Major Co-morbidities in stroke patients: a hospital based study in Bangladesh. J Dhaka Med Coll 2012, 21(1):16-20.

doi:10.1186/1756-0500-7-202

Cite this article as: Chowdhury et al:: Pattern of neurological disease seen among patients admitted in tertiary care hospital. BMC Research Notes 2014 7:202

\section{Submit your next manuscript to BioMed Central and take full advantage of:}

- Convenient online submission

- Thorough peer review

- No space constraints or color figure charges

- Immediate publication on acceptance

- Inclusion in PubMed, CAS, Scopus and Google Scholar

- Research which is freely available for redistribution 